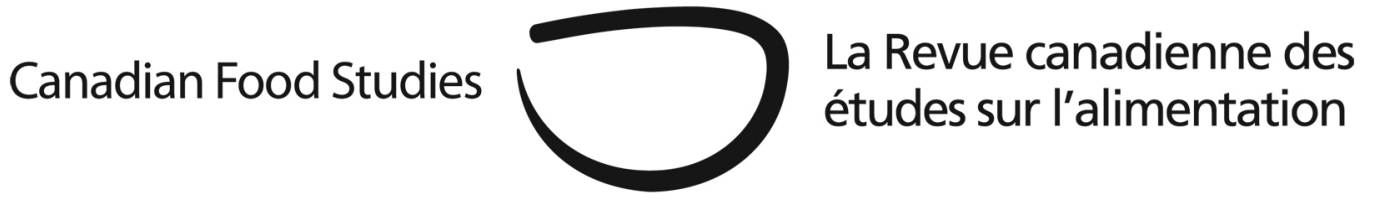

Original Research Article

\title{
Cultivating community through gardening in Kenora, Ontario
}

\author{
Rob Moquin ${ }^{a}$, Alan P. Diduck ${ }^{b}$ A. John Sinclairc, and lain J. Davidson-Hunt ${ }^{d}$ \\ aNatural Resources Institute, University of Manitoba \\ rob.moquin@gmail.com \\ ${ }^{b}$ Department of Environmental Studies and Sciences, University of Winnipeg \\ ${ }^{c, d}$ Natural Resources Institute, University of Manitoba
}

\begin{abstract}
Community gardens are places where people connect, share, and engage their social and ecological communities. The purpose of this research was to document and communicate participants' experiences of community-building through community gardening in Kenora, Ontario, Canada. The primary method used was Photovoice, whereby a group of twelve participants shared photos and stories of their garden communities in a series of workshops. Follow-up interviews were used to get participant feedback on the Photovoice process and fill gaps in the data, while participant observation was used to triangulate data. Results suggest a uniquely relational perspective of community gardening, the significance of sharing and learning in the garden, and success with and barriers to social capital and ecological citizenship among gardeners. Of particular importance, future garden initiatives in Kenora will likely require a combination of institutional and grassroots efforts to facilitate intergenerational bonding, connecting across community gardens, building gardens in accessible locations, and addressing colonial and racial barriers to collaboration.
\end{abstract}

Keywords: community gardens, social capital, ecological citizenship, community-based participatory research, Photovoice, Northwestern Ontario 


\section{Introduction}

While community gardens vary in size, allocation of space, governance, and availability of resources, they are broadly described as areas marked by some degree of democratic process, where diverse people come together to grow food and other plants (Draper \& Freedman, 2010). They also generally consist of individual and/or communal growing plots within a commonly maintained area (Drake \& Lawson, 2015).

Among their many potential benefits, community gardens can promote social connectedness and cohesion (Armstrong, 2000; Hanna \& Oh, 2000; Saldivar-Tanaka \& Krasny, 2004), positive cross-cultural interactions (Shinew, Glover \& Parry, 2004; Wakefield et al., 2007), the (re)production and dissemination of ecological knowledge (Andersson, Barthel \& Ahrné, 2007; Hale et al., 2011; Okvat \& Zautra, 2011), inclusive decision making (Glover, Shinew \& Parry, 2005), neighbourhood advocacy, and civic action (Hancock, 2001; Krasny \& Tidball, 2009b; Okvat \& Zautra, 2011). As well, they can both facilitate and depend upon the flow of knowledge and resources among individual gardeners, garden networks, and the community at large (Firth, Maye \& Pearson, 2011; Glover, Parry \& Shinew, 2005). Research shows they can provide platforms for individuals to discover and advocate for larger social and ecological communities (Krasny \& Tidball, 2009b), and create landscapes through which environmental perception and civic roles are transformed (Baker, 2004; Travaline \& Hunold, 2010). In short, community gardens can be places where people connect, share, learn, and engage with their social and ecological communities.

The purpose of this community-based participatory research was to explore local experiences of community building through community gardening in Kenora, Ontario, Canada. Specifically, we examined whether and how community gardening contributed to the production of social capital and ecological citizenship.

Community building has been defined as "neighbors learning to rely on each other, working together on concrete tasks that take advantage of new self-awareness of their collective and individual assets, and, in the process, creating human, family, and social capital that provides a new base for a more promising future” (G. T. Kingsley, McNeely \& Gibson, 1997). Social capital is a well-researched topic in both the community building and community gardening literatures. However, empirical studies of social capital among community gardeners tend to be quantitative and lack rich accounts of context. Furthermore, at its conceptual base, social capital, and much of the community-building literature, frames community in terms of what Block (2008) refers to as "relatedness" among "human systems", leaving room for envisioning more holistic and ecological interpretations of the relationships that make up a community. Ecological citizenship is a highly promising framework for addressing these shortfalls in the communitybuilding literature and conceptualizations of community in general. 


\section{Community building through gardening}

\section{Community gardens and social capital}

Social capital, or the trustworthy and reciprocal connections between individuals in social networks, is an integral component of robust communities (Manzo \& Perkins, 2006; Putnam, 2000). Communities with high levels of social capital tend to foster mutual assistance, social cohesion, sense of place, and community identity by maintaining informal networks of people with shared interests, identities, or place-based aspirations (Firth et al., 2011; Manzo \& Perkins, 2006). Although social capital remains a contested term (Manzo \& Perkins, 2006; Walsh, 2011), Putnam (2000) and Woolcock (2001) agree on two types of social capital: "bonding” and "bridging” social capital. These, along with "linking” social capital are central when considering communities of interest such as community gardens, as well as the social capital they retain. (See Table 1 in Analysis for the types of social capital examined in this study and the indicators used to identify them.)

Bonding social capital refers to trust and reciprocity between individuals who share strong social ties, such as culture, kinship, socioeconomic status, or neighbourhood affiliation. Through these ties, community members exchange resources, knowledge and skills, maintain a sense of community, and reaffirm their membership in it. Community gardens facilitate bonding social capital by providing opportunities for families and close friends to share the experience and enjoyment of gardening (J. Y. Kingsley \& Townsend, 2006), sustain cultural ties and preserve related ecological knowledge (Saldivar-Tanaka \& Krasny, 2004), receive trusted moral support in challenging times (J. Y. Kingsley \& Townsend, 2006), and celebrate shared success (Firth et al., 2011; Saldivar-Tanaka \& Krasny, 2004).

Bridging social capital describes the reciprocal and trustworthy relationships that develop between individuals of differing socio-economic experience. These relationships facilitate the flow of resources and knowledge between diverse groups with a common interest (Firth et al., 2011; Manzo \& Perkins, 2006; Putnam, 2000). Bridging social capital emerges when individual gardeners or gardening groups, despite dissimilarities in class, culture, (dis)ability, or location, build relationships based on a mutual interest in gardening and its shared benefits (Firth et al., 2011; Glover et al., 2005; J. Y. Kingsley \& Townsend, 2006).

Linking social capital refers to one's capacity to leverage decision-makers, knowledgekeepers, or resource-holders. Through such linkages, community members are able to gain access to resources and have impact on decisions that have bearing on their lives and well-being (Firth et al., 2011; Woolcock, 2001). Community gardens can bring together community groups, non-profit organizations, government agencies, and educational institutions (Krasny \& Tidball, 2009a; Richardson, 2011) around building strong social and ecological communities, often relying on government, corporate, or organizational support through financing, in-kind 
assistance, or policy reform (Firth et al., 2011). Those with decision-making power, knowledge, or resources gain social credit in exchange for their support (Firth et al., 2011).

It should be noted that the strong and intimate connections that constitute bonding social capital can also result in the exclusion of those who do not identify with the in-group (Firth et al., 2011; Glover, 2004; J. Y. Kingsley \& Townsend, 2006; Shinew et al., 2004). Furthermore, how one understands and gains access to social capital is mediated by social position and ethnic identity, with marginalized community gardeners having generally less access to social networks and resources than their more privileged counterparts (Walsh, 2011).

\section{Community gardens and ecological citizenship}

Ecological citizenship, or the integration of social and environmental values through ecological practices like community gardening, is an essential aspect of building broad and robust communities (Krasny \& Tidball, 2009a). Rather than framing urban landscapes as built environments inhabited by largely disconnected populations (Light, 2003), ecological citizenship compels us to think of our human environments - urban or otherwise - in terms of relationships among and between people, other species, and the earth itself (Okvat \& Zautra, 2011). This holistic view of community blurs the line between society and environment, and can result in people acting together in new ways towards social and environmental community-building goals (Armstrong, 2000; Ohmer et al., 2009; Richardson, 2011; Travaline \& Hunold, 2010). See Table 2 in Analysis for the aspects of ecological citizenship examined in this study (described below) and the indicators used to identify them.

Ecological citizenship frames social-ecological knowledge and skills, such as those developed through community gardening, as the basis for building socially and ecologically robust communities. Community gardeners learn about the plants, insects, practical gardening techniques, local vegetation, climate, ecosystem services, and the best crops to grow under these conditions (Baker, 2004; Krasny \& Tidball, 2009a; Shava et al., 2010). They also learn about each other, cultural practices, food preferences (Wakefield et al., 2007), and social-ecological issues such as food insecurity in their communities (Armstrong, 2000; Richardson, 2011). Furthermore, community gardeners often develop capacities for organizing, advocacy, decision making, and governance (Baker, 2004; Hancock, 2001; Krasny \& Tidball, 2009b; Wakefield et al., 2007), as well as the self-confidence to apply these capacities to further community-building activities (Ohmer et al., 2009; Travaline \& Hunold, 2010).

This knowledge and skill-building is reproduced through imitation, communication, sharing, and collective ritual in the physical space of the garden (Barthel, Folke \& Colding, 2010) and other public and private spaces, such as community kitchens, where community gardeners convene (Glover et al., 2005; Mundel \& Chapman, 2010). Community gardeners thus participate in communities of practice, through which action and the reification of socialecological knowledge, skills, capacities and related action can result in positive community 
outcomes, such as improved ecosystem services, positive social outcomes, and enhanced community well-being (Barthel et al., 2010; Krasny \& Tidball, 2009a).

Of particular importance to this research, community gardens can provide opportunities for people to develop ecological citizenship in common with gardeners from different regions or cultures. Individuals who migrate from rural to urban settings, or across regional or national boundaries, often maintain culturally diverse, experiential, or practical agricultural knowledge that can be applied to new gardening contexts (Krasny \& Tidball, 2009a; Shava et al., 2010). By sharing food and knowledge across cultural boundaries, community gardeners are introduced to new foods and cooking techniques (Hancock, 2001; Travaline \& Hunold, 2010; Wakefield et al., 2007) and set the stage for the production of further social capital, learning, cross-cultural cohesion, and community building (Richardson, 2011; Saldivar-Tanaka \& Krasny, 2004).

Research design

\section{Context}

Kenora is a city of nearly 16,000 full-time residents (City of Kenora, 2014), located in Northwestern Ontario, near the Manitoba border. Kenora has long been known for its pristine lakes and cottage life; during the summer, its population more than doubles as part-time residents take up residence in cottage country. Surrounded by several First Nations in Treaty \#3 territory, Kenora is also home to many Indigenous people who live in the city, either part of the year or year-round. With a diverse and fluctuating population, Kenora hosts a vibrant food community that includes urban farmers, market vendors, and community gardens (Moquin, 2014).

The majority of community gardens in Kenora are operated by community organizations on private lands. These gardens are designed to promote skills, capacity, community and inclusion specifically among the people they serve. Examples include the community gardens operated by Kenora Association for Community Living, Women’s Place Kenora, Changes Recovery Homes, and Waasegiizhig Nanaandawe'Iyewigamig Health Access Centre. Other examples of community gardening are found on private property throughout Kenora, such as at Gardner House and Benidickson Court seniors’ apartments. Although the City of Kenora’s official plan refers to promoting and identifying municipal cites for community gardening, Rabbit Lake Community Garden remains the only community garden located on municipal land and managed by participating gardeners (City of Kenora, 2015; Moquin, 2014).

This study was done under the auspices of the Common Ground Research Forum, a fiveyear community-university research alliance supported by the Social Sciences and Humanities Research Council of Canada. The alliance partners were the City of Kenora, Grand Council of Treaty \#3, three Anishinaabe First Nations (Obashkaandagaang, Ochiichagwe'babigo'ining, Wauzhushk Onigum) and two universities (Manitoba and Winnipeg). The goals of the alliance 
were to understand and build capacity for collaboration and social learning across Indigenous and settler populations, recognizing that Indigenous people have historically been excluded from resource management and agricultural opportunities afforded to settlers in the region (DavidsonHunt, 2003; Waisberg \& Holzkamm, 1993). The activities of the alliance included issuing calls for community-based research proposals, and working with those involved to develop and implement their proposals.

Our study stems from this process, and is founded on a three-year research relationship we established with the Arts Hub (the Hub) ${ }^{1}$. Operated by the Kenora Association for Community Living (KACL), the Hub promotes valued social roles for people with disabilities, and helps build inclusive community through arts-based programming and community events (Kenora Association for Community Living, 2008; 2014). In 2010, the Hub added container gardening to its suite of activities, and has since worked to expand its garden programming and networks. In 2012, it built an accessible garden (with raised beds and paved aisles) and subsequently hosted an annual series of garden workshops. In late 2012, we began discussions with Hub management and staff about partnering on a community-based participatory research project to investigate the contributions of community gardening to community building in Kenora.

\section{Photovoice}

We chose Photovoice as the primary data collection and analysis technique because it includes community members in data collection, analysis, and dissemination, and promotes community ownership of knowledge and outcomes. It also matched the Hub's interest in action research and complemented its arts-based mandate for community building (personal communication with Lisa Gate-Villa, KACL Manager 2012).

Photovoice is an innovative and participatory approach to research whereby a group of community participants use photography, stories, and public art to identify and engage community strengths and areas for actionable change (Palibroda et al., 2009; Wang \& Burris, 1997). Photovoice participants are, therefore, repositioned as co-researchers. They guide the identification of themes and subjects that are photographed, produce and collect data by taking pictures of relevant phenomena in their environment, and discuss these as a group. They then analyze the data in partnership with the lead researcher, and actively participate in dissemination of findings through public exhibition and community engagement (Wang \& Burris, 1997). Through this participatory process, Photovoice participants create and communicate knowledge on issues of particular interest to themselves and their fellow community members. Photovoice participants can facilitate social change by exposing a broader range of actors, including policyand decision-makers, to the valuable knowledge and insightful experiences of participant-

\footnotetext{
${ }^{1}$ http://www.kacl.ca/index.php/ojb/departments/options-for-adults/community-participation-and-support/arts-hub.
} 
researchers (Castleden, Garvin \& Huu-ay-aht First Nation, 2008; Nykiforuk, Vallianatos \& Nieuwendyk, 2011; Wang \& Burris, 1997; Wang \& Redwood-Jones, 2001).

\section{Participants and process}

Rather than purposeful sampling for Photovoice, Palibroda et al. (2009) recommend using a variety of formal and informal methods to recruit participants who are passionate about the research topic, diverse in experience, and ready to work for long-term change. With this approach, the lead researcher is responsible for ensuring that participants are aware of the commitment involved, consent to the project goals, and understand their responsibility for the direction of the project.

The principal investigator and Hub personnel administered the Photovoice process. We initially distributed electronic and hard copies of an invitation to Hub patrons who were known to garden at the Hub or elsewhere. However, to promote the Hub's goals of being an inclusive community and building ongoing collaborative partnerships between community gardens and gardening organizations, we forwarded invitations to community gardeners throughout Kenora.

The final group of 12 participants included people from four community gardens managed by local organizations, a combination of Indigenous and settler gardeners, and individuals with diverse intellectual abilities and experience with gardening and photography. Although slightly larger than the seven to ten participants recommended by Palibroda et al. (2009), the group of 12 offered a diversity of perspectives, as well as opportunities to collaborate with various organizations and gardeners throughout Kenora.

Photovoice participants attended an orientation meeting to document their informed consent, receive their cameras ${ }^{2}$, participate in a photography workshop, and obtain the first of four photography assignments that they would complete over the next four weeks. Assignments for weeks two, three, and four were decided by the Photovoice group. The assignments were as follows:

1) My Garden Community. The first assignment was designed to let participants explore elements of their garden community that are meaningful to them.

2) Relationships. For their second assignment, participants chose to explore the social and ecological relationships that make up their garden communities.

3) Other People’s Gardens. Participants photographed other people's gardens as a way to highlight community assets and discover new sources of ideas and knowledge.

\footnotetext{
${ }^{2}$ Digital cameras were given to all participants as compensation for participation. Meals were served at each meeting. Transportation by taxi and child-minding were available at no cost.
} 
4) Sharing Our Potential: Sharing and potential were common themes in the first three workshops. In the final week, participants investigated both themes in greater detail.

The Photovoice group met for weekly workshops at the Hub, at which they shared their photos and stories and engaged in a facilitated discussion on the weekly assignment theme. Participants were not expected to attend every workshop, and attendance ranged from six to nine participants at each workshop. Discussions involved identifying key narratives that emerged from the photos and accompanying stories. The Photovoice workshops were audio recorded and transcribed, and the transcripts given to participants for verification.

After all assignments were completed, photographs and key narratives were compiled into a public exhibit so that the group could communicate to the public what they had learned. The exhibit, titled "Growing together: Cultivating community through gardening," included 38 photographs and accompanying stories from eight of the participants (all 12 participants were given the option to add their photographs). To help achieve knowledge mobilization, the exhibit was launched at an open house at the Hub, in September 2013, where it was covered by local media. The following week, it was prominently featured at the Matiowski Farmers' Market, and was later installed for a year at the Kenora Recreation Centre. The exhibit returned to the Hub in August 2014. Throughout its year-long travels, the exhibit generated positive responses from viewers. As one participant pointed out in her interview with Kenora Online, "I think people are really impressed. When you see the pictures blown up, you just see how much beauty there is there and how people interpret the different concepts of gardening. So far I'd say the response has been very positive” (Judy Underwood quoted in Harris, 2013).

\section{Supplementary methods}

Participant observation and follow-up interviews were used to fact-check data and triangulate findings that emerged from the Photovoice component of the research. Participant observation included participation in and observation of garden maintenance (i.e., sowing, weeding, watering, harvesting) and garden-related celebrations (i.e., community feasts and harvest celebrations). Semi-structured follow-up interviews were conducted with participants to get feedback on the suitability of Photovoice for this research and what participants liked best and least about it, as well as to elicit further data on research themes not covered, or of emerging interest, in the workshop setting.

Specifically, participants were asked about connections to decision-makers and people with resources (linking social capital), social exclusion in gardening groups, skill development through gardening, and successes in and opportunities for cross-cultural collaboration. Of the 12 participants, six provided follow-up interviews, one participant declined an interview (and did 
not give a reason), and five did not respond to our request. As with Photovoice workshops, interviews were audio recorded and transcribed, and the transcripts given to participants for verification.

\section{Analysis}

If academic concepts such as social capital, which are often unfamiliar to community gardeners and research participants, are to be useful, they must be firmly situated in local context and responsive to ethno-cultural and socio-economic differences (Walsh, 2011). As such, the verified workshop transcripts were coded according to ideas and terms that emerged during workshop discussions. Relying on grounded theory techniques (Corbin \& Strauss, 2014), coded data were then grouped into major themes that corresponded to the Photovoice assignments. The themes were synthesized into a plain language community report that was given to participants for verification. Five participants provided feedback on the report during follow-up interviews and three did so by email. Interview transcripts and observation notes were later coded according to the same framework as the Photovoice data and integrated into the results. This analysis resulted in a set of locally contextualized results, previously published in Moquin (2014).

Table 1: Analytical framework for social capital

$\begin{array}{lll}\text { Type Description } & \text { Indicators }\end{array}$

\begin{tabular}{lll}
\hline & Trust and reciprocity among existing & $\bullet$ Reciprocity among family and friends \\
Social & social groups (J. Y. Kingsley \& & $\bullet$ Trust among family and friends \\
Bonding & Townsend, 2006; Putnam, 2000) & $\bullet$ Bonding opportunities
\end{tabular}

\begin{tabular}{llll}
\hline & Trust and reciprocity among diverse & \\
Social & people with a common interest (J. Y. & $\bullet$ Reciprocity among diverse gardeners \\
Bridging & Kingsley \& Townsend, 2006; Putnam, & $\bullet$ Trust among diverse gardeners \\
& 2000).
\end{tabular}

Social Linking

Access to resources from institutions and decision-makers (Firth et al., 2011; Woolcock, 2001)
- Support from the city

- Support from business

- Support from local organizations

- Schools and workplace initiatives

- Linking opportunities
Social Exclusion
Exclusion from strongly bonded groups and lack of access to networks or resources (Glover, 2004; J. Y. Kingsley \& Townsend, 2006)
- Exclusion from strongly bonded groups

- Exclusion from networks or resources 
These contextualized results were then analyzed according to frameworks for social capital and ecological citizenship, each of which consisted of four major components, several subcomponents, and related indicators. Given the dearth of qualitative research on social capital (J. Y. Kingsley \& Townsend, 2006), a framework for analysis was developed specifically for this project (Table 1), based on the literature presented above. The four major categories were: social bonding, social bridging, social linking, and social exclusion. As for ecological citizenship (Table 2), major categories included: social-ecological knowledge, skills, action, and crosscultural collaboration.

While the frequency of discussion or unanimity of opinion may provide valuable insights into predominant or shared experiences, we acknowledge the noteworthiness of minority, conflicting, or idiosyncratic perspectives (e.g., Miles, Huberman \& Saldaña, 2014). That said, notation was made of how many participants spoke about each indicator and, where relevant, these quantities are noted in the results section as follows: one participant, two participants, some participants (three to five), half of participants (six), most participants (seven to eleven), and all participants (twelve).

Participants were given the option to use their real names or pseudonyms for direct quotations. All photography is attributed to participants and is used with their permission.

Table 2: Analytical framework for ecological citizenship

\begin{tabular}{lll}
\hline Aspect & Description & \multicolumn{1}{l}{ Indicators } \\
\hline & & $\bullet$ Knowledge of people \\
Social- & Local knowledge of people, plants, ecosystems for & $\bullet$ Plant knowledge \\
ecological & building robust communities (Krasny \& Tidball, & $\bullet$ Food knowledge \\
knowledge & 2009a; 2009b; Shava et al., 2010; Wakefield et al., & $\bullet$ Animal knowledge \\
& 2007) & $\bullet$ Local environmental knowledge \\
& & $\bullet$ Knowledge opportunities \\
\hline
\end{tabular}

Skills and capacities as growers and community

Skills organizers developed through community - Practical gardening skills gardening (Baker, 2004; Hancock, 2001; Krasny

- Communicative/organizing skills \& Tidball, 2009b; Wakefield et al., 2007).

Application of skills and capacities towards action • Capacity-building, access to food

Action on social and ecological issues (Baker, 2004; - Beautification and urban pride Hancock, 2001; Krasny \& Tidball, 2009b;

- Environmental stewardship Wakefield et al., 2007).

- Action opportunities

$\begin{array}{ll}\begin{array}{l}\text { Cross- } \\ \text { cultural }\end{array} & \begin{array}{l}\text { Introduction to new foods, knowledge, and skills } \\ \text { through sharing food and knowledge across }\end{array} \\ \text { collaboration } & \text { cultures (Hancock, 2001; Travaline \& Hunold, } \\ & \text { 2010; Wakefield et al., 2007). }\end{array}$

- Cross-cultural collaboration (general)

- Indigenous-settler collaboration

- Cross-cultural opportunities 


\section{Results}

\section{Setting the context}

All participants in this study revealed that, through community gardening, they interacted within a social-ecological system that included the people, plants, animals, and environmental conditions that contribute to the production of food, medicines, and ornamentals in the community. According to participants, these relationships and the sharing, cooperation, and learning that transpired through them were a defining feature of community gardening.

"I always bring friends up to my garden plot, and talk them into helping me out. And then they get to take some of it home when they go" (Fay, August 1, 2013).

"[A good friend of mine] has really nice plants and lots of veggies and that stuff, from gardening... We share some veggies together” (Johanna, August 22, 2013).

"I realized that a little sunflower plant had sprouted from the work of the squirrels and the chipmunks. So at first, I started plucking them out. And then I thought, 'No. That doesn't feel right. I'm just going to let them grow.' And that was sharing” (Judy, August 22, 2013).

"I used to come out of sweats [and] lay on the grass just like that, and I'm thinking, 'Take care of me. Hug me. You know more than I do.' I wouldn't want to invade this space, because it's beautiful the way it is. Because in that space, there's an ecosystem: there's a whole bunch of insects and all different life forms that are living in that area” (Mother, August 22, 2013).

Community building was fostered through a variety of gardening practices that transpired, not only in conventional community gardens, but also in the natural, private, market, and public gardens that contribute to a robust community gardening landscape. Conventional community gardens included the shared spaces where people come to grow plants in individual or communal plots, as described in the introduction. Natural gardens included the plants and foods found outside of cultivated garden settings, such as berries, mushrooms, onions, rosehips, and medicines like sage and blueberry.

“The onions are natural. We've got a lot of berries, too” (Tom, August 22, 2013). 


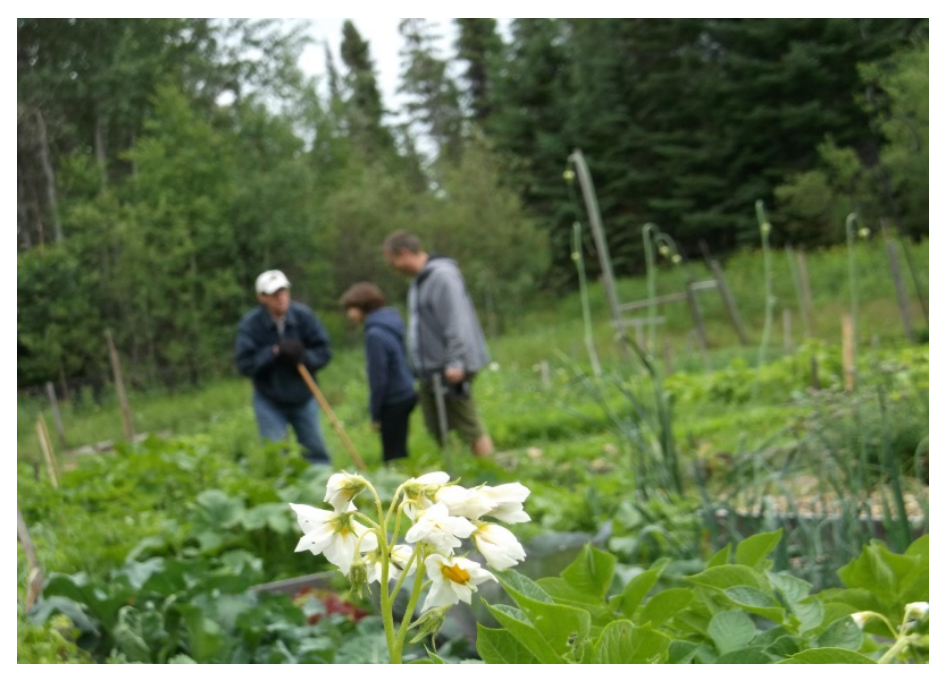

Figure 1: Sharing Success $(\subset)$ 2013 by Fay Clark. Gardeners converse about vegetables and weed management.

Figure 2: Rabbit Lake Community Garden (c) 2013 by Meg Wheatstone. Rabbit Lake Community Garden is the only conventional community garden in Kenora on city land and managed by gardeners.

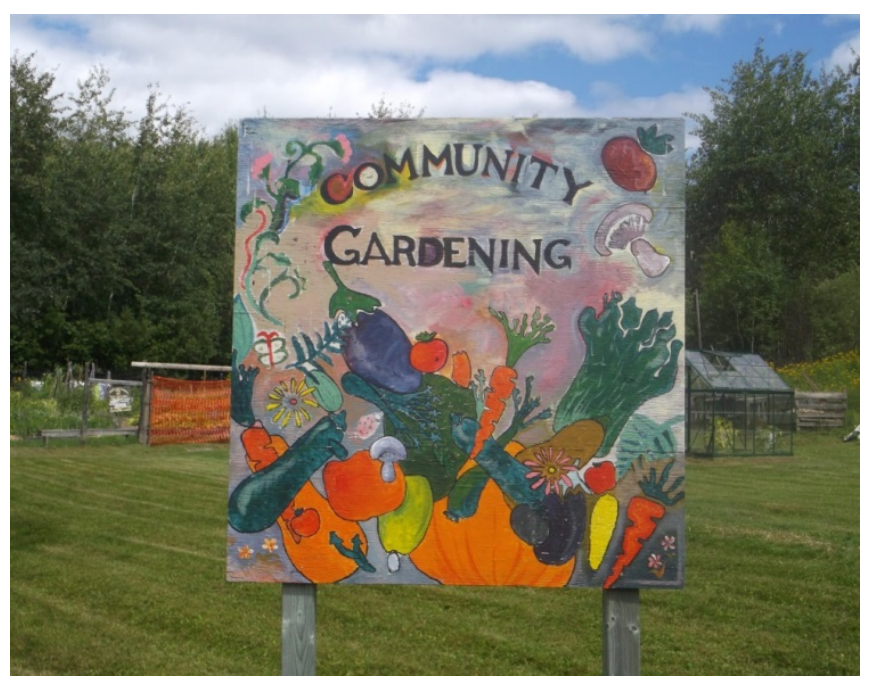

Gardeners often cooperated, learned, and shared with their families and neighbours in private gardens, which participants considered a form of community gardening.

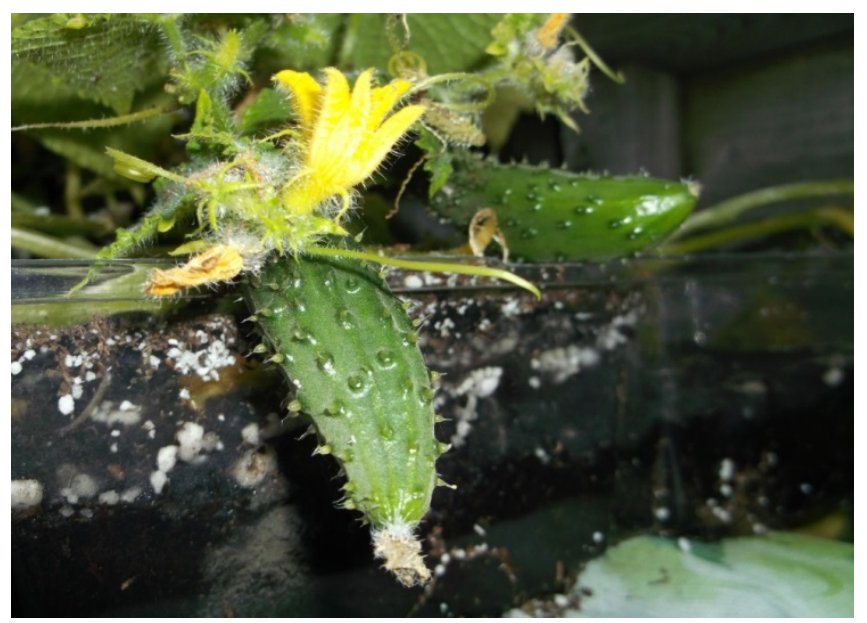

Figure 3: Good Things / Small Containers (C) 2013 by Judy Underwood. Judy started cucumbers from seed. With too many plants and not enough containers, she traded plants for pots with her neighbour. 
Market gardeners grow and sell their produce locally in market gardens, and contribute to a sustainable and innovative community garden landscape. “[One market gardener's] idea is to allow more people to have the experience to grow gardens. And it's not just a raised garden, it is waist high. He has several active gardens right now using that construction, and what he's recycling is the old palettes. So the materials are basically free... And he's thinking, because [if you cannot] bend down...you can continue enjoying gardening, and he's making it possible for them" (Leanne, August 22, 2013).

Although tended by municipal employees, public gardens were known to be enjoyed by the public and community and have the potential to produce food.

"[The McLeod Park gardens are] part of the community, where community members and tourists come to that particular spot to take pictures” (Mercedes, August 15, 2013).

All participants recognized success and growth in their garden communities, and throughout the garden landscape. According to participants, gardens provided places to gather and share; enjoyment for gardeners and visitors; connection to nature and beauty; opportunities for relaxation, personal time, and play; a source of meaning, purpose, pride and accomplishment; increased food skills and capacity; and access to healthful food and physical activities.

"[The garden provides] access to safe, affordable, culturally appropriate food [and] is a means for people to take control of their own lives... and grow the food that they want to grow” (Judy, August 8, 2013).

"It's part of a food security program. [They] have fresh produce, and also helping them with skills and increasing their self-reliance and self-esteem” (Mercedes, August 1, 2013).

"The garden feels good for everybody: because they eat healthy, and [develop] strong bones, and exercise every day" (Johanna, August 15, 2013).

"It's important to note that we have successes in community gardening, and that it makes our city beautiful. And that it's possible, as well. So, I think that seeing it as a success and possibly building on it is something that we should consider" (Fay, August 22, 2013). 


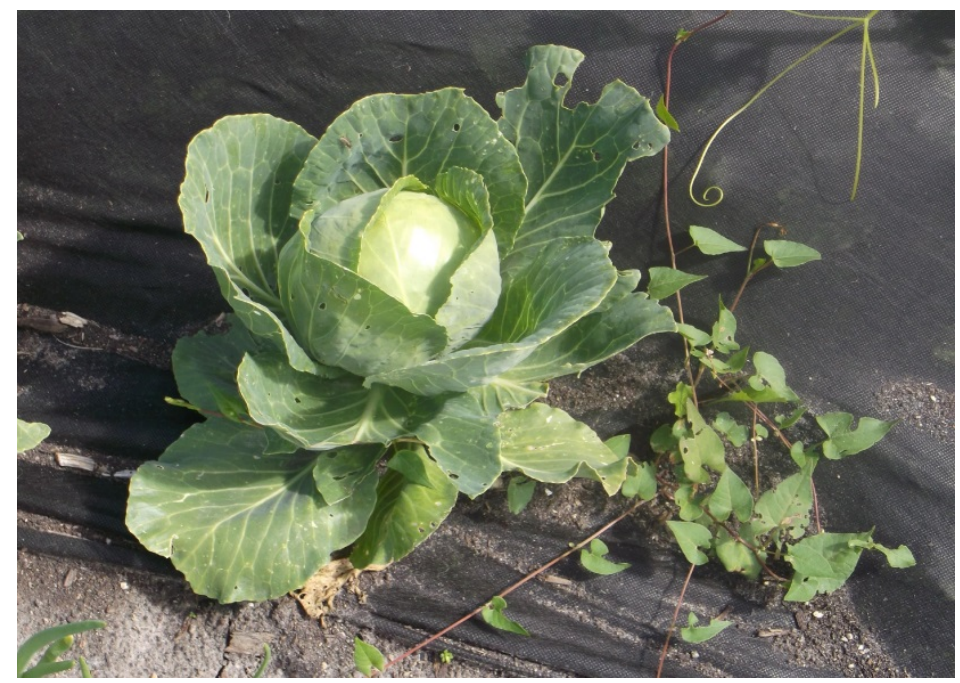

Figure 4: Heads Up! (C)

2013 by Meg

Wheatstone. Among

their many benefits,

community gardens

provide healthful foods

like this head of

cabbage.

Some participants also saw a need not just for more community gardens, but for gardens located in places that are accessible to those who could most use them. They recognized that existing ornamental garden beds and grassy boulevards in central, high-traffic areas could be used to grow edibles as well, and saw food production on municipal land as a way to bring people together, beautify the city, and improve access to food and gardens.

A vegetable garden that's central that everybody could get to [would be a good addition] (Fay, August 22, 2013).

[There are many] flowers along the harbourfront... Wouldn't it be great if, amongst the flowers, there [were] some vegetables, and people were free to pick and eat them? (Judy, September 10, 2013).

Figure 5: Beautiful Potential (C) 2013 by Judy Underwood. Flower boxes near the harbourfront could be used to grow vegetables for consumption by restaurants, community groups, and even passers-by.

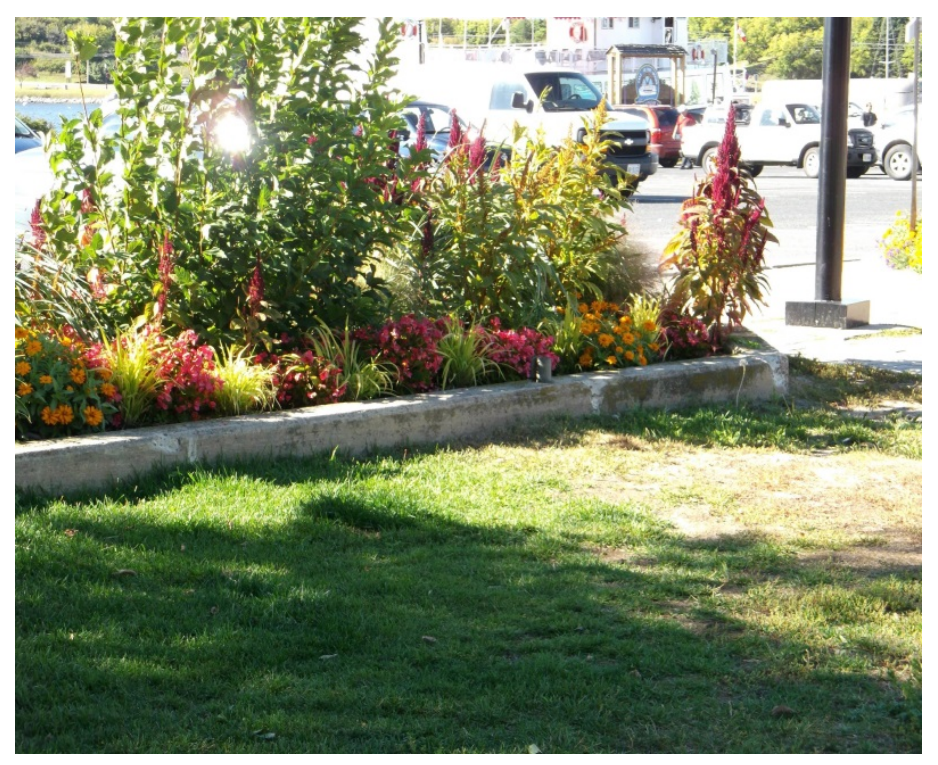




\section{Community gardening and social capital}

This section summarizes the degree to which social capital—bonding, bridging, linking, and social exclusion - was evident in participant narratives of community gardening. It also outlines evidence regarding opportunities for enhancing those social capital characteristics (see Table 3).

Table 3: Evidence of social capital through gardening and related activities

\begin{tabular}{|c|c|c|}
\hline Type & Indicators & Summary of Findings \\
\hline \multirow{3}{*}{$\begin{array}{l}\text { Social Bonding } \\
\text { Reciprocity and trust } \\
\text { among family and friends }\end{array}$} & Bonding reciprocity & $\begin{array}{l}\text { Shared responsibilities, time, energy, knowledge, } \\
\text { produce; satisfaction, fulfilment, self-worth in } \\
\text { exchange for efforts }\end{array}$ \\
\hline & Bonding trust & $\begin{array}{l}\text { Trust in family and friends to provide gardening } \\
\text { knowledge or help maintain the garden; } \\
\text { dependability }\end{array}$ \\
\hline & Bonding opportunities & $\begin{array}{l}\text { Intergenerational learning and knowledge; } \\
\text { preservation of gardening culture }\end{array}$ \\
\hline \multirow{3}{*}{$\begin{array}{l}\text { Social Bridging } \\
\text { Reciprocity and trust } \\
\text { among diverse people } \\
\text { with a common interest } \\
\text { in gardening }\end{array}$} & Bridging reciprocity & $\begin{array}{l}\text { Shared responsibilities, time, energy, knowledge, } \\
\text { and resources among new gardening acquaintances }\end{array}$ \\
\hline & Bridging trust & $\begin{array}{l}\text { Trust in others' knowledge; open to conversation; } \\
\text { letting others harvest from plots }\end{array}$ \\
\hline & Bridging opportunities & $\begin{array}{l}\text { Expanding social bridges; developing more urban } \\
\text { gardens to build bridges }\end{array}$ \\
\hline \multirow{5}{*}{$\begin{array}{l}\text { Social Linking } \\
\text { Access to resources from } \\
\text { institutions, decision- } \\
\text { makers, and people with } \\
\text { power }\end{array}$} & Support from the city & $\begin{array}{l}\text { Donation of land for Rabbit Lake Community } \\
\text { Garden; public municipal gardens for tourism and } \\
\text { beautification }\end{array}$ \\
\hline & Support from business & Donation of garden inputs (plants, mulch) \\
\hline & $\begin{array}{l}\text { Support from local } \\
\text { organizations }\end{array}$ & $\begin{array}{l}\text { Community gardens governed by a local } \\
\text { organization }\end{array}$ \\
\hline & $\begin{array}{l}\text { Schools and workplace } \\
\text { initiatives }\end{array}$ & $\begin{array}{l}\text { Successful and upcoming initiatives in schools and } \\
\text { workplaces }\end{array}$ \\
\hline & Linking opportunities & $\begin{array}{l}\text { Greater support and direct involvement by city and } \\
\text { businesses; investment potential of gardens; space, } \\
\text { funding, management support; grassroots } \\
\text { initiatives may be preferable to formal support }\end{array}$ \\
\hline \multirow{2}{*}{$\begin{array}{l}\text { Social Exclusion } \\
\text { Social barriers to } \\
\text { bonding, bridging, and } \\
\text { linking }\end{array}$} & $\begin{array}{l}\text { Exclusion from strongly } \\
\text { bonded groups }\end{array}$ & $\begin{array}{l}\text { Exclusion of Indigenous and other racialized } \\
\text { groups; hesitance to share knowledge outside of } \\
\text { family and close friends }\end{array}$ \\
\hline & $\begin{array}{l}\text { Exclusion from networks } \\
\text { or resources }\end{array}$ & Transportation \\
\hline
\end{tabular}




\section{Social bonding}

All participants spoke of how community gardening and related activities brought families and friends together. Reciprocity through gardening was evident in the responsibilities, time, energy, knowledge, and produce shared among family and friends. Some gardeners derived a sense of fulfilment or self-worth in exchange for their efforts. Gardeners trusted their family and friends to provide gardening knowledge or help maintain the garden.

"[My husband] knew everything and taught me... But this year, I had to go on a trip back to Guatemala. So I didn't have time to plant. So he did it this year" (Mercedes, August 1, 2013).

"I had extra plants, so I shared some with my neighbour next door. I didn't have enough containers, so she gave me some” (Judy, August 1, 2013).

“Because I'm in a blended family, I thought, 'Well this is going to help my family, it's going to help his family”” (Mother, August 8, 2013).

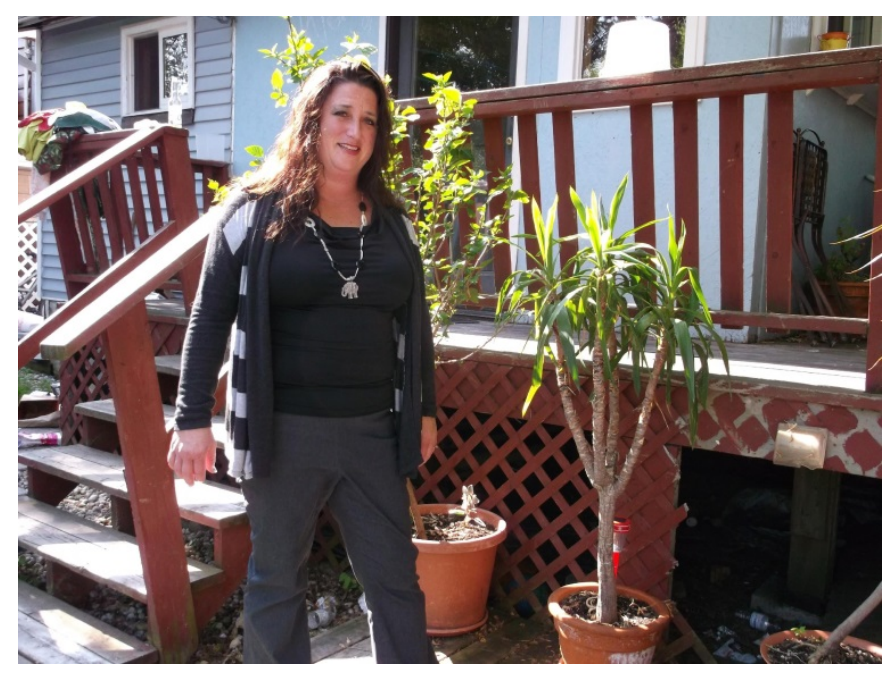

Figure 6: Family and Friends Working Together in the Garden on a Summer Day (C) 2013 by Johanna Hendrickson. Johanna's good friend, Terra, has gardened for a long time. They garden and cook together.

\section{Social bridging}

Most participants described community gardens as places that bring diverse people together. They talked about meeting and getting to know new people through these activities. As with family and friends, connections with fellow gardeners and new acquaintances provided an opportunity to develop reciprocity and trust in the gardens through shared responsibilities, time, energy, knowledge, and resources. Gardeners demonstrated trust in other gardeners' knowledge 
about gardening and food, and indicated this by engaging in conversations, new experiences, or allowing community members access to the garden.

"Very nice people help the garden grow...help it clean up, help mow the lawn” (Meg, September 10, 2013).

"It's more interesting when you have a lot of people that are involved with gardening... It helps out quite a bit, anyway, for sure” (Tom, August 8, 2013).

"Whenever you pick that sage, you just take the leaf buds and you sprinkle them. You do the same thing with sweet grass... Other people are going to come” (Mother, August 22, 2013).

"The intention of the garden was for sharing, for whoever saw something that they wanted. They were free to take it” (Judy, August 15, 2013).

\section{Social linking}

Half of the participants noted the importance of public municipal gardens to tourism and beautification, and that the City of Kenora and local businesses supported community gardens and green spaces to some degree. Access to municipal land for the Rabbit Lake Community Garden and donations of garden inputs by local businesses were two common examples of this support. Furthermore, the majority of the community gardens in Kenora were governed by local community organizations. Opportunities to garden required having linkages with these governing organizations and, in some cases, participating in other programming. Some participants noted the relevance of gardening at schools and workplaces and spoke of successful and upcoming initiatives.

"[Businesses] have an interest in making Kenora a place that is beautiful, that is self-sustaining... Some people in that particular group are really community-minded, and they really want growth and success in the community” (Participant 1, March 17, 2014).

"The Fellowship Centre, which has a garden; [WNHAC], which has a workplace garden; KACL, which has a community garden; the seniors' blocks and supportive housing, some of them do have garden plots... Valley View: they're doing the outdoor classroom. They want to have a garden component to that” (Judy, January 31, 2014). 


\section{Social capital opportunities}

Despite the evidence of linking noted above, some participants noted that the city could do more to promote gardening, including creating more gardens and direct involvement of city councillors in community gardening activities. Restaurants, for their part, could promote more gardening by growing their own produce. However, these participants noted the difficulty in getting decision-makers to support these types of initiatives. They thought that gardens may not be seen as a sound business investment by restaurants or the city. And although there were successful workplace gardens in Kenora, participants often spoke of challenges in establishing a garden at their own workplace. These challenges included lack of space or funding and getting decision-makers on board.

"If you invest in land and growing things, it's a slow process and there are some teachings or preparation. And that would take more of their time, interest, or money. And I don't think that would provide them with a return. So I don't think that's something that is in their priorities” (Participant 1, March 17, 2014).

"I would love to start [a garden] at our workplace, because there is some space there available. But it's selling people on the idea and figuring out a way to work with the landlord to do that” (Judy, August 15, 2013).

Some participants suggested that grassroots action and existing garden networks may be more effective than top-down planning and policy change since other gardeners are a source of new ideas and knowledge. Some participants knew, or knew of, master gardeners in their community, and most expressed interest in getting connected with other gardeners and sharing what they learn.

"It's important to also remember other community gardeners who may be well positioned. Getting to know others in the garden may be a great source of knowledge and resources” (Fay, paraphrased, January 17, 2014).

“[Gardeners at seniors' residences] will have lots of tips and knowledge of how to [garden], if they did it all their lives when they owned a home or when they were living in a particular community” (Mercedes, August 15, 2014).

"We should kind of map [the community gardens] out, because they're our assets in the community that we can build on" (Judy, August 22, 2013). 
Figure 7: Henry the Innovator (C) 2013 by Leanne Wheatstone. Many participants described learning from fellow gardeners throughout the community, such as Henry, a well-known gardener, educator, and food activist.

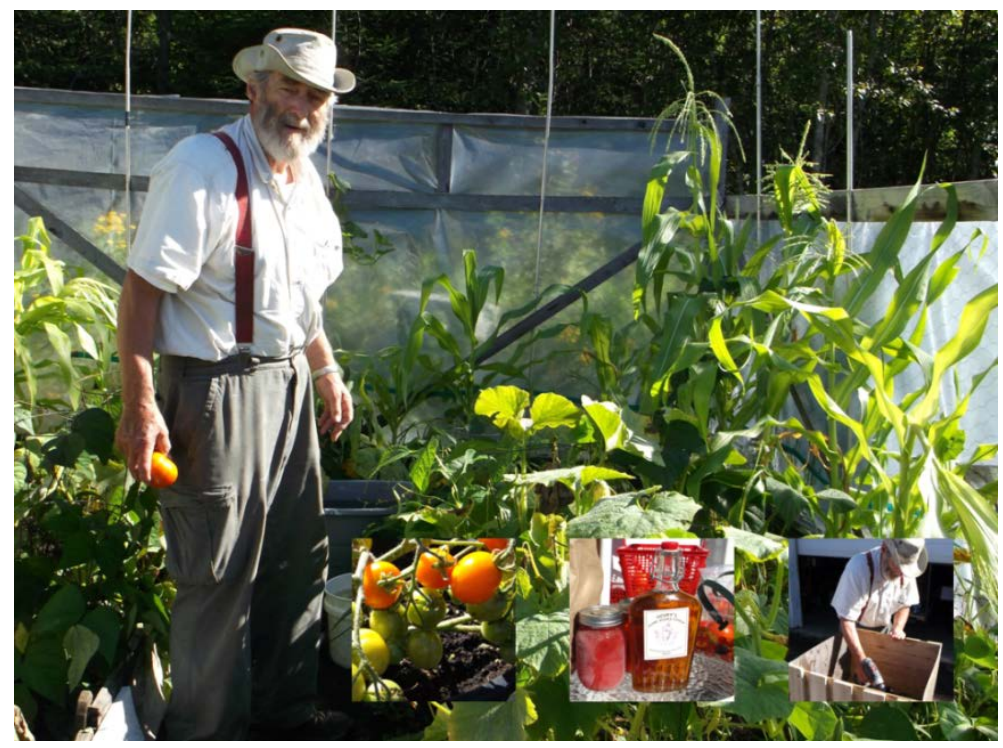

As noted above, social bonding was particularly strong among family and friends who gardened together, and most participants spoke eagerly of ideas and aspirations that would enhance bonding capital, such as their future garden plans, and a desire to promote gardening and share gardening knowledge with their families and communities. Intergenerational learning and passing on knowledge and skills to the next generation was considered key to ensuring greater engagement in gardening and preservation of various cultural and gardening practices by most participants.

"I’m looking forward to teaching this to my kids [and] keep this going... I know they both like planting, and they love bugs and everything” (Nick, August 1, 2013).

"[We share what] our grandparents told us, our mentors told, our sisters, our mothers... I share with my daughter [and] I would like her to pass those [teachings] on to my grandchildren and my greatgrandchildren” (Mother, August 22, 2013).

"It made me think about how families used to garden, and how they used their space and their land to provide food... And I thought, 'Wow! How we've lost that sense of backyard gardens'” (Judy, August 15, 2013). 


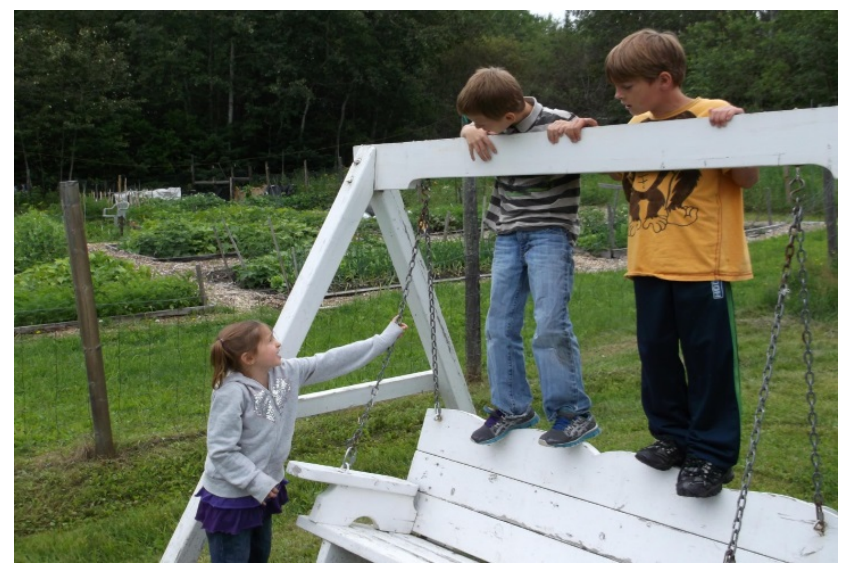

Social exclusion
Figure 8: Light Gardening? (C) 2013 by Fay Clark. When they are not busy on the swing, Fay's children and their friend help out in the garden. Fay hopes that they will learn about food and gardening from being around it, just like she did as a child.

Most participants described gardens as inclusive places that bring diverse community members together through common activities and goals. However, one participant noted that some Indigenous and other racialized people feel excluded from some gardening activities that are dominated by white Euro-Canadian gardeners.

Some participants critiqued the ability of community gardening to break down barriers, noting that strong relationships in the garden may require a pre-existing connection, such as membership in a strongly bonded group. Two participants suggested that transportation may be the most pressing barrier to having access to gardens, networks, and resources. Without access to a vehicle, it was difficult for some potential gardeners to get to a place where they can garden. Lack of suitable transportation impeded gardeners from visiting and sharing with other gardeners, as most of the participants expressed their intentions to do.

"[The gardeners] are always welcoming and smiling” (Johanna, January 17, 2014).

"There are so many, especially First Nations people in Kenora, who don't feel part of the community. They don't participate in community gardens, because they don't feel like their opinions matter” (Participant 1, March 17, 2014).

"Many of the people in and around Kenora that could benefit from more gardening don't have access to a vehicle. Transportation barriers are often ignored in here, because everyone is thought to have a car” (Fay, paraphrased, January 17, 2014).

\section{Ecological citizenship}

This section outlines the degree to which ecological citizenship — knowledge, skills, action, and cross-cultural collaboration-was evident in participant narratives of community gardening. It 
also summarizes opportunities for enhanced individual and intergenerational learning, further action on community gardening, and improved cross-cultural collaboration. Opportunities related to skills were not explicitly discussed. Table 4 provides a summary of the indicators and evidence of ecological citizenship and of opportunities for its enhancement.

Table 4: Evidence of ecological citizenship

\begin{tabular}{|c|c|c|}
\hline Component & Indicators & Summary of Findings \\
\hline \multirow{6}{*}{$\begin{array}{l}\text { Social-ecological knowledge } \\
\text { Knowledge of the people, } \\
\text { plants, animals, and local } \\
\text { environments that make up } \\
\text { one's community }\end{array}$} & Knowledge of people & $\begin{array}{l}\text { Knowledge of friends, family, other gardeners; } \\
\text { learning about each other }\end{array}$ \\
\hline & Plant knowledge & $\begin{array}{l}\text { Knowledge of plants, characteristics, services, } \\
\text { relationships, health, care }\end{array}$ \\
\hline & Food knowledge & $\begin{array}{l}\text { Knowledge of food preferences, quality, } \\
\text { harvesting; trouble identifying food }\end{array}$ \\
\hline & Animal knowledge & Knowledge of animals and insects, services, pests \\
\hline & $\begin{array}{l}\text { Local environmental } \\
\text { knowledge }\end{array}$ & $\begin{array}{l}\text { Knowledge of local environment, conditions, } \\
\text { regional differences }\end{array}$ \\
\hline & Knowledge opportunities & $\begin{array}{l}\text { A desire to learn more; pass on knowledge to } \\
\text { future generations; culture change }\end{array}$ \\
\hline \multirow{3}{*}{$\begin{array}{l}\text { Skills } \\
\text { Practical expertise with } \\
\text { gardening or acquired } \\
\text { through gardening }\end{array}$} & $\begin{array}{l}\text { Practical gardening } \\
\text { expertise }\end{array}$ & $\begin{array}{l}\text { Practical skills related to gardening and garden } \\
\text { maintenance; food preparation skills }\end{array}$ \\
\hline & $\begin{array}{l}\text { Communicative and } \\
\text { organizing skills }\end{array}$ & $\begin{array}{l}\text { Community engagement and organizing around } \\
\text { social-ecological issues }\end{array}$ \\
\hline & Skills opportunities & Not explicitly discussed \\
\hline \multirow{2}{*}{$\begin{array}{l}\text { Action } \\
\text { Taking action on social- } \\
\text { ecological issues in the } \\
\text { community }\end{array}$} & $\begin{array}{l}\text { Positive outcomes of } \\
\text { garden-related action }\end{array}$ & $\begin{array}{l}\text { Enhanced capacity and access to food and } \\
\text { gardens; urban beautification; environmentally } \\
\text { responsible gardening practices }\end{array}$ \\
\hline & Action opportunities & $\begin{array}{l}\text { Environmental stewardship and culture change; } \\
\text { more gardening on the urban landscape }\end{array}$ \\
\hline \multirow{3}{*}{$\begin{array}{l}\text { Cross-cultural } \\
\text { collaboration } \\
\text { People from different } \\
\text { cultures cooperating, sharing, } \\
\text { or learning together }\end{array}$} & $\begin{array}{l}\text { Cross-cultural } \\
\text { collaboration (general) }\end{array}$ & $\begin{array}{l}\text { When cooking and eating in restaurants, with } \\
\text { friends, and at community food events }\end{array}$ \\
\hline & $\begin{array}{l}\text { Indigenous-settler } \\
\text { collaboration }\end{array}$ & $\begin{array}{l}\text { Cross-cultural influences on gardening and food; } \\
\text { cross-cultural community food events }\end{array}$ \\
\hline & $\begin{array}{l}\text { Cross-cultural } \\
\text { opportunities }\end{array}$ & $\begin{array}{l}\text { Better understanding of others' cultural food } \\
\text { practices and preferences; more investment of } \\
\text { time, energy, and outreach }\end{array}$ \\
\hline
\end{tabular}




\section{Social-ecological knowledge}

Participants in this study demonstrated a wealth of social and ecological knowledge, foundational to understanding and addressing issues of community importance, conceiving of community in holistic terms, and being creative in what building community might entail. In addition to knowledge of the other people in their community (see Social capital, above), all participants demonstrated some knowledge of the local plants, animals, and environmental conditions. Most demonstrated a capacity to identify and manage the plants and food items in and around their gardens, as well as articulate taste and quality.

"I guess the plants were kind of dusty, like it needed some moisture... I just kind of figured they were thirsty, so we watered them down” (Tom, August 8, 2013).

"You take pride in what you grow. It tastes so much richer" (Mercedes, August 8, 2013).

“If you're not [familiar] with it, you can’t pick [mushrooms]. It's not the same as looking in a book, [so] I'm teaching as many people as I can” (Fay, August 22, 2013).

Figure 9: Untitled 2 (C) 2013 by Jeremy Muckuck. When Jeremy cracked his first pea pod, he was surprised by the space between the peas.

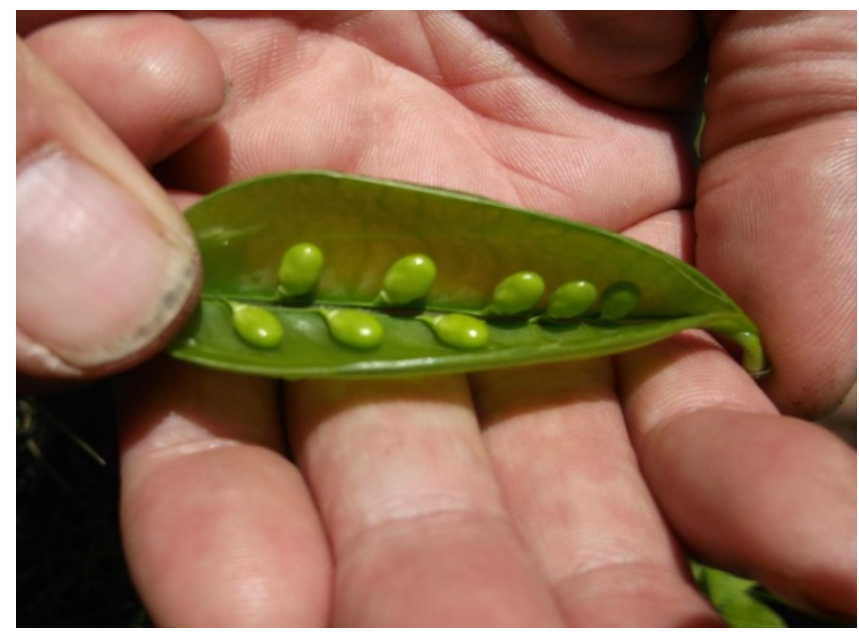

Most participants demonstrated knowledge of their relationships with the animals and insects with which they share the garden. They recognized that some plants and animals provide ecological services, while others may be pests. Regardless, they are all part of the garden community. Most participants noted the importance of local environment conditions. They recognized the value of water, sunlight, and healthy soil for their gardens, as well as how growing conditions are different in different places. 
"The bees on the flower get nectar to make honey, pollinate the flowers... They're pollinating lupines, and making some honey, because it's food for bees” (Meg, August 1, 2013).

“I just hope [the groundhog] doesn't take all our carrots underground. That's alright though. Having little critters come around the garden makes it more interesting” (Tom, August 1, 2013).

"It's a beautiful spot to have a garden. It has westerly exposure, and the lake is right there. So, it's easily watered and the soil must be nice and moist” (Fay, August 15, 2013).

"Water is life: is what sustains us, and is what sustains our gardens... And knowing that you don't put any pesticides and you're not causing more damage to the land, than already has" (Mercedes, August 8, 2013).

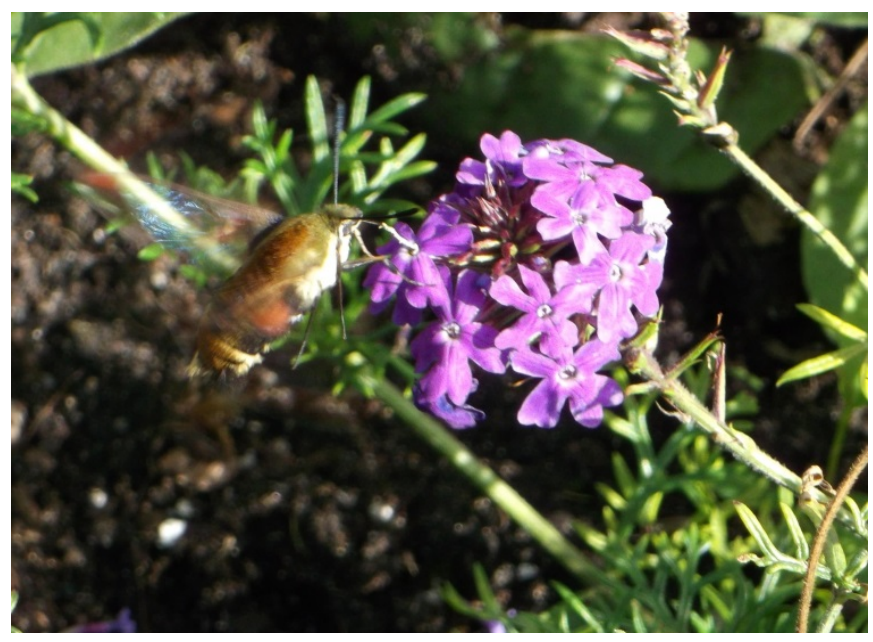

Figure 10: Alien Among Us (C) 2013 by Leanne Wheatstone. Pollinators provide essential services to gardens.

\section{Skills}

While not extensively discussed, most participants gave examples of practical skills they learned related to garden preparation, maintenance, harvesting, and food preparation. Generally speaking, most participants recognized community gardening as a great way to develop these skills. Furthermore, two participants learned organizing or advocacy skills through their involvement in community gardening. 
"Many of the women that [garden here] are struggling with food. So it's part of a food security program, and also have fresh produce, and also helping them with skills and increasing their self-reliance and selfesteem” (Mercedes, August 1, 2013).

"It was building that sense of community, of pulling neighbours together that might not, as a whole, collectively have gotten together" (Judy, January 31, 2014).

"I learned community advocacy and using conversation to stress the positive outcomes of community gardening” (Fay, paraphrased, January 17, 2014).

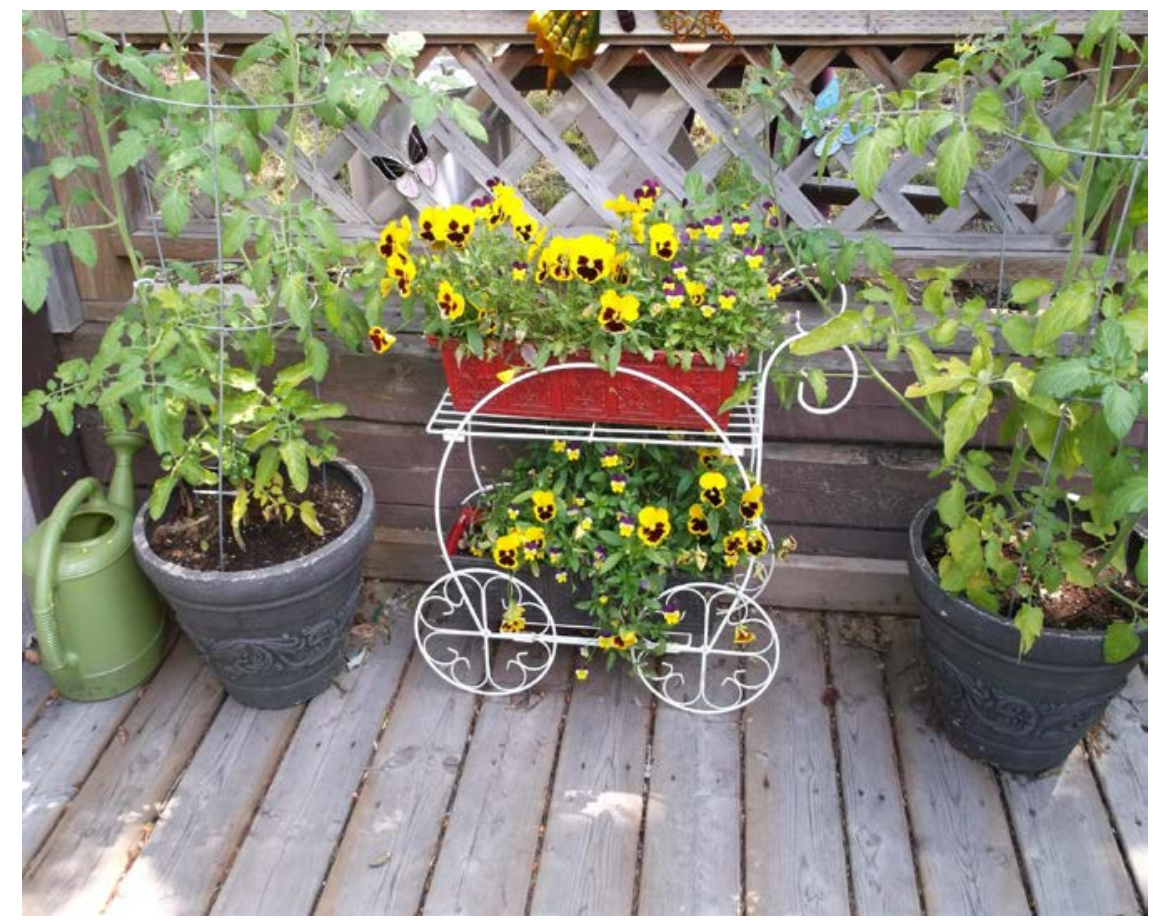

Figure 11: Family and Friends Working Together in the Garden on a Summer Day 4 (C) 2013 by Johanna Hendrickson. Johanna grows flowers and vegetables with her mom, like these tomatoes and pansies. Working with her mother, aunt, and several friends, Johanna has learned an assortment of gardening skills.

\section{Action}

Most participants pointed to new and existing institutions, organizations, and people who have taken action, through gardening, to create change in their communities. Many participants noted enhancements in access to food and gardening as a result of recent and positive developments. Some participants identified the role of gardens and gardeners in beautifying the city, and the 
importance of celebrating such achievements. Many participants spoke of preserving the natural environment through gardening practices, and caring for the resources used in the garden (e.g., land, soil, water).

“[This garden promotes] access to safe, affordable, culturallyappropriate food. [It] is a means for people to take control of their own lives, and grow their own food, and grow the food that they want to grow" (Judy, August 8, 2013).

"He has several active gardens right now using that construction [by which] you can stand and garden. And he's thinking-because people, physically, as they age or for whatever reason they run into an issue that they can't bend down-here's your option. You can continue enjoying gardening. He's making it possible for them" (Leanne, August 22, 2013).

"I think [the flower baskets] are a community asset and, as far as I can tell, it's going well, because there are several throughout the community. And I think it's important to note that we have successes in community gardening, and that it makes our city beautiful” (Fay, August 22, 2013).

"Well, if you compost, then that's less material that's going to the landfill, which definitely benefits the environment. My neighbour, who would bag up her leaves that would go in the garbage, now come in my yard. Because I do have a pile where, over the last three years, the leaves have been composting” (Judy, January 31, 2014).

"[My husband] planted the milkweed to get the monarch butterflies to come. He orchestrated parts of the garden for different reasons” (Leanne, February 1, 2014).

\section{Cross-cultural collaboration}

Cross-cultural collaboration through gardening was not discussed much in the workshop setting. Food-based collaboration was largely confined to restaurants, when cooking and eating with friends, and at community food events. Yet when asked specifically about Indigenous-settler collaboration in interviews, all interviewees (half of the participants) were able to identify some examples of cross-cultural influences on gardening and food, as well as several cross-cultural community food events. 
“We don't know where everything comes from, but there are cultural influences all around. For example, Aboriginal peoples gave us smoked fish" (Summary from interview with Fay, January 17, 2014).

“And we've always picked berries, as a kid growing up. So that's one of their traditions, too, in the [Indigenous] community... And wild rice: we enjoy wild rice” (Leanne, February 1, 2014).

"There were some workshops held in Kenora, and [an Indigenous elder] came and spoke to us. That was really significant. I think it's a good way for people to start thinking about food in a different way, when you're exposed to food from different cultures... I think of the three sisters gardening and the companion gardening with the corn, squash, and beans, and thinking about how I can incorporate that into my garden” (Judy, January 31, 2014).

\section{Ecological citizenship opportunities}

In terms of knowledge and action opportunities, some participants understood local gardening culture to be in jeopardy. Some suggested that a change of culture is what is needed to ensure a better relationship with the environment and resources, and saw opportunities for learning and teaching in the garden, especially across generations. Some participants advocated explicitly for the use of environmentally responsible gardening practices, wherever possible. (See also Social capital opportunities, above, for opportunities related to passing on garden-related knowledge to children and developing the urban gardening landscape).

"It's about changing the culture and the community, and getting people just engaged in whatever ways they can” (Judy, January 31, 2014).

"I think that the kids in school now are learning a lot about the environment, about recycling, about composting... I think there are opportunities to share more information” (Participant 1, March 17, 2014).

"There is a lot of water in this area [now], but...what is going to happen when that resource becomes scarce, too? [We should use it] to the maximum, the natural [source] when it rains... gather the water” (Mercedes, August 8, 2013). 
Figure 12: Natural Relationships 3 @ 2013 by Mercedes Alarcón. A lily opens after a rain shower, demonstrating our dependence on water.

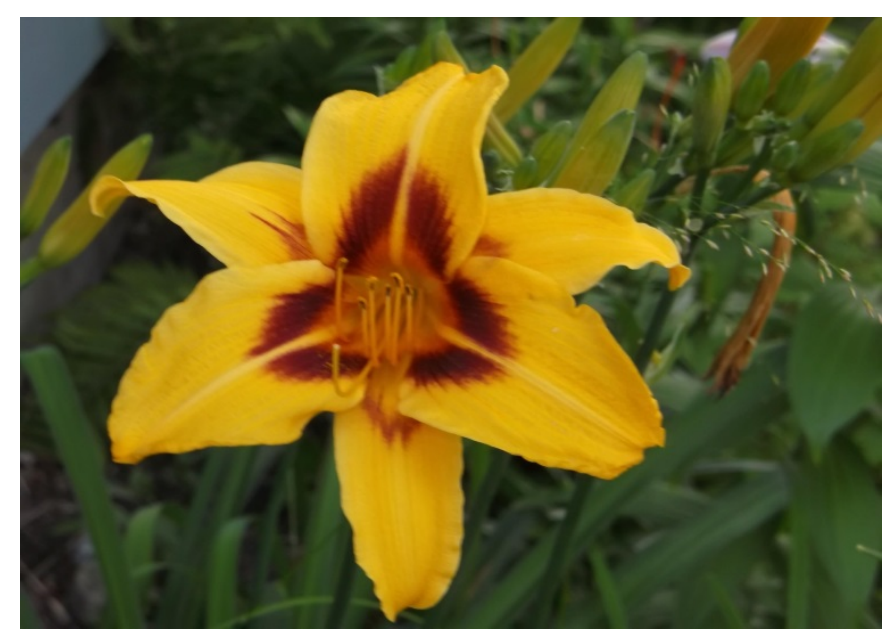

In terms of opportunities for cross-cultural collaboration, some participants noted a lack of understanding in regards to the cultural origins and benefits of food plants and practices. Some others were more vocal about racial tensions that exist in Kenora, and their impact on potential collaboration within the community (See also Social exclusion, above). Overcoming these obstacles was seen as requiring a greater investment of time and energy. As initiatives tended to draw the same group of concerned individuals, outreach to the wider community was viewed as equally necessary.

"I would say there's a fair lack of understanding. I mean, I know a lot of people who wouldn't be able to understand why there would be tobacco growing in a vegetable garden: because of it being a sacred gift” (Judy, January 31, 2014).

"[Because of] racist and discriminatory [attitudes, some people are] missing those opportunities to learn something different... We can create those opportunities, but it's a matter of making the time and investment” (Participant 1, March 17, 2014).

"Striking conversations among people from various cultures is important. It will also be important to reach out to other people, besides the 'usual suspects'” (Fay, paraphrased, January 17, 2014).

\section{Discussion and conclusions}

As noted earlier, community gardens are meant to be inclusive places, marked by some degree of democratic process, where diverse people come together to grow food and other plants (Draper \& Freedman, 2010). However, the results presented here suggest a uniquely relational view of community gardening, in which individuals interact with a social-ecological community of 
people, plants, animals, and environmental conditions that contribute to the availability of food, medicines, and ornamentals. From this perspective, gardening happens and community building can occur whenever and wherever community members gather to grow food and other plants, organize and feast, or simply enjoy locally grown plants and produce. This could take the form of conventional community gardens, public gardens, markets, natural gardens, or private spaces.

\section{Social capital and community gardening}

Similar to findings by Walsh (2011, p. 194), the majority of participants were unfamiliar with the term social capital, yet their narratives clearly demonstrated evidence of its occurrence. Participants drew attention to the relational characteristics of community gardens, as well as the role of reciprocity and trust among families, friends, other gardeners, and the community at large. The results show that community gardening in Kenora provided opportunities for family and friends to bond through shared experience and enjoyment. Gardens were also venues for neighbourhood events that helped build community by promoting connectedness and social bridging. Similar results have been documented in a variety of locations, including Toronto (Wakefield et al., 2007), New York City (Saldivar-Tanaka \& Krasny, 2004), Melbourne, Australia (J. Y. Kingsley \& Townsend, 2006), and Nottingham, UK (Firth et al., 2011). Moreover, not confined to the physical space of the garden, bridging social capital was exercised and community building occurred through enhanced relationships among gardening groups, organizations, and individuals with similar interests (see also Firth et al., 2011).

Intergenerational bonding and cultural preservation through gardening was of particular importance in Kenora. Social bonding was found to be particularly strong among family and friends who garden together, and passing on knowledge and skills to the next generation was considered key to ensuring greater engagement in gardening and preservation of various cultural and gardening practices. This finding parallels results by Saldivar-Tanaka and Krasny (2004) in their research among Latino gardeners in New York. In this and our case, children were not necessarily required to garden, but rather their presence in the garden was seen as sufficient to immerse them in-and therefore preserve-gardening culture and knowledge. Such cultural preservation enhances the potential for future cross-cultural bridging and community building.

Similar to findings by Glover et al. (2005) and J. Y. Kingsley and Townsend (2006), the study demonstrates that community gardening can help bridge the gap between diverse gardening groups. It is clear that there is potential to learn and generate new ideas by getting connected to other gardeners throughout Kenora. This knowledge can then be applied to one's own gardening context, among one's friends and family, or for the betterment of one's community. Participants recognized the diversity of garden types that make up the community garden landscape as a rich source of bridging social capital. In other words, connections can be made and community building can occur in community gardens, but also in private yards, market gardens, public gardens, or common foraging grounds. 
Similar to findings by Firth et al. (2011), Richardson (2011), and Krasny and Tidball (2009a), linking social capital was evident in the various relationships between gardening groups and local institutions, such as the City of Kenora, local businesses, community organizations, schools, and workplaces. And while bridging through garden networks may prove more valuable for maintaining a thriving community garden landscape, enhanced supports from local government and business are necessary for identifying and developing more places for community gardens. According to participants, there is a need for not just more community gardens, but gardens that are located in places that are accessible to those who could most use them. Similar to Mikulec et al. (2013), we found that distance, mobility barriers, and/or lack of access to reliable transportation can inhibit potential gardeners who live far from existing community gardens. Overcoming these barriers is important for strengthening gardening's potential as a platform for building community.

\section{Ecological citizenship and community gardening}

Participants also recognized that community garden relationships extend beyond the social, and include complex ecological relationships with the plants, animals, and environmental systems that make up, and contribute to, their garden communities. These results illustrate gardening's potential for enabling the development of more holistic and sustainable conceptions and perceptions of community. They also highlight the need and opportunities for fresh views on what constitutes community building. By engaging ecological relationships alongside their social counterparts, and thus practicing ecological citizenship, community gardeners further socialecological well-being (Okvat \& Zautra, 2011) and (re)produce experiential and observational knowledge of their communities and social-ecological impacts (Krasny \& Tidball, 2009a).

Consistent with previous studies on the social and ecological aspects of community gardening, this research shows that community gardens provide a place to (re)produce knowledge on the ecological processes that transpire in the garden (Krasny \& Tidball, 2009a; 2009b), the connections between gardening and the local environment (Baker, 2004; Shava et al., 2010), and gardening and food preparation techniques (Hancock, 2001; Mundel \& Chapman, 2010; Wakefield et al., 2007).

Participants in this research recognized that sharing knowledge in and of the garden can enhance capacities and contribute to healthy environments and ecosystems services (see also Barthel et al., 2010; Hancock, 2001; Krasny \& Tidball, 2009b). They understood that community gardens can be a platform from which to develop practical gardening expertise and/or organizational skills, and facilitate positive outcomes for their gardens and socialecological communities (see also Ohmer et al., 2009; Okvat \& Zautra, 2011; Travaline \& Hunold, 2010).

Our results, added to research by Baker (2004), Okvat and Zautra (2011), and SaldivarTanaka and Krasny (2004), demonstrate the potential for community gardens to expand our notions of community building and to contribute to culturally diverse landscapes that reflect the 
preferences and needs of culturally diverse gardeners. Nevertheless, actualization of such outcomes was not evident in the present research study. In fact, while many white EuroCanadian participants viewed community gardens as bringing diverse community members together through common activities and goals, and providing opportunities for people to feel part of a community, some racialized community members continued to feel excluded from some community gardening initiatives. These challenges to bridging and community building through gardening - the result of colonialism and racism, among other factors-are by no means unique to Kenora, but reveal the potential of community gardening to reinforce social divisions through the exclusion of those not in the gardening or cultural in-group (Firth et al., 2011; Glover, 2004; J. Y. Kingsley \& Townsend, 2006; Shinew et al., 2004). There is much work to overcome these obstacles, but participants generally felt that better understanding of others' cultural food practices and preferences as well as greater investment of time and energy into outreach by white Euro-Canadian gardeners to Indigenous and racialized newcomer gardeners were integral to bridging these gaps. Workshops and other shared gardening and food experiences that intentionally seek to facilitate cross-cultural collaboration and include diverse participation were more effective at bridging than simply sharing community garden space.

\section{Concluding comments}

Through community gardening and related activities, participants demonstrated an ability to develop and maintain strong social and ecological relationships and in doing so helped build their communities. Social bonding among family and friends through gardening was commonly cited, and is particularly important for passing on gardening knowledge. This is important considering the loss, over the past several decades, of a general gardening culture in Canadian cities. Social bridging with other gardeners happens in some cases, and remains a clear priority for many participants. As ecological citizens, gardeners understand the social and ecological aspects of their communities, and many possess a wealth of knowledge and skills for broadening and diversifying conventional conceptions of community and familiar approaches to building community. Additionally, through their actions, community gardeners enhance access to food, build community capacity, care for their environments, and manage natural resources.

Furthermore, this research demonstrates that there are challenges to community building through community gardening in Kenora. According to participants, transportation, the location of gardens, insufficient municipal and institutional support, and systemic barriers to social inclusion are among the challenges confronting community gardeners. While they may not agree or have all of the answers, the participants in this research provided valuable information as to why these challenges exist and how they may be overcome. According to their diverse insights, it will likely require a combination of institutional and grass-roots efforts to expand community gardening in Kenora, make gardens more accessible, and address colonial and racial barriers to connecting and collaborating. 
That said, the insights provided by the participants in this research offer valuable advice for developing the community gardening landscape, planning future garden programming in Kenora, and continuing to build community. Their participation in the research demonstrates the unique and varied forms that community garden action can take. As an extension of their gardening activities, participants used Photovoice to not only describe, but also shape their garden communities, and perhaps inspire others to do the same.

\section{References}

Andersson, E., Barthel, S., \& Ahrné, K. (2007). Measuring social-ecological dynamics behind the generation of ecosystem services. Ecological Applications, 17(5), 1267-1278.

Armstrong, D. (2000). A Survey of community gardens in Upstate New York: Implications for health promotion and community development. Health and Place, 6(4), 319-327.

Baker, L. E. (2004). Tending cultural landscapes and food citizenship in Toronto's community gardens. Geographical Review, 94(3), 305-325.

Barthel, S., Folke, C., \& Colding, J. (2010). Social-ecological memory in urban gardensRetaining the capacity for management of ecosystem services. Global Environmental Change, 20(2), 255-265. doi: 10.1016/j.gloenvcha.2010.01.001

Block, P. (2008). Community: The Structure of Belonging. San Francisco: Berrett-Koehler Publishers.

Castleden, H., Garvin, T., \& Huu-ay-aht First Nation. (2008). Modifying Photovoice for community-based participatory Indigenous research. Social Science \& Medicine, 66(6), 1393-1405. doi: http://dx.doi.org/10.1016/j.socscimed.2007.11.030

City of Kenora. (2014). Strategic Plan: 2015 to 2020. Toronto: Urban Metrics Inc.

City of Kenora. (2015). Official Plan. Ottawa.

Corbin, J. M., \& Strauss, A. (2014). Basics Of Qualitative Research: Techniques and Procedures for Developing Grounded Theory (4th Ed.). Los Angeles: Sage.

Davidson-Hunt, I. J. (2003). Indigenous lands management, cultural landscapes and Anishinaabe people of Shoal Lake, Northwestern Ontario, Canada. Environments, 31(1), 21-41.

Drake, L., \& Lawson, L. J. (2015). Results of a US and Canada community garden survey: shared challenges in garden management amid diverse geographical and organizational contexts. Agriculture and Human Values, 32(2), 241-254. doi: 10.1007/s10460-0149558-7 
Draper, C., \& Freedman, D. (2010). Review and analysis of the benefits, purposes, and motivations associated with community gardening in the United States. Journal of Community Practice, 18(4), 458-492. doi: 10.1080/10705422.2010.519682.

Firth, C., Maye, D., \& Pearson, D. (2011). Developing “community” in community gardens. Local Environment, 16(6), 555-568. doi: 10.1080/13549839.2011.586025

Glover, T. D. (2004). Social capital in the lived experiences of community gardeners. Leisure Sciences, 26(2), 143-162.

Glover, T. D., Parry, D. C., \& Shinew, K. J. (2005). Building relationships, accessing resources: Mobilizing social capital in community garden contexts. Journal of Leisure Research, 37(4), 450-474.

Glover, T. D., Shinew, K. J., \& Parry, D. C. (2005). Association, sociability, and civic culture: the democratic effect of community gardening. Leisure Sciences, 26(2), 75-92. doi: 10.1080/01490400590886060

Hale, J., Knapp, C., Bardwell, L., Buchenau, M., Marshall, J., Sancar, F., \& Litt, J. S. (2011). Connecting food environments and health through the relational nature of aesthetics: Gaining insight through the community gardening experience. Social Science and Medicine, 72(11), 1853-1863. doi: 10.1016/j.socscimed.2011.03.044

Hancock, T. (2001). People, partnerships and human progress: Building community capital. Health Promotion International, 16(3), 275-280. doi: 10.1093/heapro/16.3.275

Hanna, A. K., \& Oh, P. (2000). Rethinking urban poverty: A look at community gardens. Bulletin of Science, Technology \& Society, 20(3), 207-216. doi: 10.1177/027046760002000308

Harris, B. (2013, September 26). Focus on Community Gardening. from http://www.kenoraonline.com/index.php?option=com_content\&view=article\&id=6481:fo cus-on-community-gardening\&catid=1:local-news\&Itemid=158

Kenora Association for Community Living. (2008). Mission Statement. Retrieved October 10, 2012, from http://www.kacl.ca/index.php/ojb/about-kacl/mission-statement

Kenora Association for Community Living. (2014). Arts Hub: Exploring Creativity Together. Retrieved May 15, 2014, from http://www.kacl.ca/index.php/ojb/departments/optionsfor-adults/community-participation-and-support/arts-hub

Kingsley, G. T., McNeely, J. B., \& Gibson, J. O. (1997). Community Building: Coming of Age. Washington, DC: Development Training Institute \& The Urban Institute.

Kingsley, J. Y., \& Townsend, M. (2006). 'Dig in’ to social capital: Community gardens as mechanisms for growing urban social connectedness. Urban Policy and Research, 24(4), 525-537. doi: 10.1080/08111140601035200 
Krasny, M. E., \& Tidball, K. G. (2009a). Applying a resilience systems framework to urban environmental education. Environmental Education Research, 15(4), 465-482. doi: 10.1080/13504620903003290

Krasny, M. E., \& Tidball, K. G. (2009b). Community gardens as contexts for science, stewardship, and civic action learning. Cities and the Environment, 2(1), Article \#8, pp. 18.

Light, A. (2003). Urban Ecological Citizenship. Journal of Social Philosophy, 34(1), 44-63. doi: $10.1111 / 1467-9833.00164$

Manzo, L. C., \& Perkins, D. D. (2006). Finding common ground: The importance of place attachment to community participation and planning. Journal of Planning Literature, 20(4), 335-350.

Mikulec, P., Diduck, A. P., Froese, B., Unger, H., \& MacKenzie, K. (2013). Legal and policy barriers to community gardening in Winnipeg, Canada. Canadian Journal of Urban Research, 22(2), 69-89.

Miles, M. B., Huberman, A. M., \& Saldaña, J. (2014). Qualitative Data Analysis: A Methods Sourcebook (3rd Edition ed.). Los Angeles: Sage Publications.

Moquin, R. L. J. (2014). Growing Together: Cultivating Community through Gardening in Kenora, Ontario. (Master of Natural Resources Management), University of Manitoba, Winnipeg. Retrieved from http://hdl.handle.net/1993/30136

Mundel, E., \& Chapman, G. E. (2010). A decolonizing approach to health promotion in Canada: The case of the Urban Aboriginal Community Kitchen Garden Project. Health Promotion International, 25(2), 166-173. doi: 10.1093/heapro/daq016

Nykiforuk, C. I. J., Vallianatos, H., \& Nieuwendyk, L. M. (2011). Photovoice as a method for revealing community perceptions of the built and social environment. International Journal of Qualitative Methods, 10(2), 103-124.

Ohmer, M. L., Meadowcroft, P., Freed, K., \& Lewis, E. (2009). Community gardening and community development: Individual, social and community benefits of a community conservation program. Journal of Community Practice, 17(4). doi: 10.1080/10705420903299961

Okvat, H. A., \& Zautra, A. J. (2011). Community gardening: A parsimonious path to individual, community, and environmental resilience. American Journal of Community Psychology, 47(3/4), 374-387. doi: 10.1007/s10464-010-9404-z.

Palibroda, B., Krieg, B., Murdock, L., \& Havelock, J. (2009). A Practical Guide to Photovoice: Sharing Pictures, Telling Stories and Changing Communities. Winnipeg: Prairie Women's Health Centre of Excellence. 
Putnam, R. D. (2000). Bowling Alone: The Collapse and Revival of American Community. New York: Simon \& Schuster.

Richardson, T. (2011). At the Garden Gate: Community Building Through Food: Revisiting the Critique of 'Food, Folk and Fun' in Multicultural Education, Springer Science \& Business Media B.V 43, 107-123.

Saldivar-Tanaka, L., \& Krasny, M. E. (2004). Culturing community development, neighborhood open space, and civic agriculture: The case of Latino community gardens in New York City. Agriculture and Human Values, 21, 399-412.

Shava, S., Krasny, M. E., Tidball, K. G., \& Zazu, C. (2010). Agricultural knowledge in urban and resettled communities: Applications to social-ecological resilience and environmental education. Environmental Education Research, 16(5-6), 575-589. doi: 10.1080/13504622.2010.505436

Shinew, K., Glover, T., \& Parry, D. (2004). Leisure space as potential sites for interracial interaction: Community gardens in urban areas. Journal of Leisure Research, 36(3), 336355.

Travaline, K., \& Hunold, C. (2010). Urban agriculture and ecological citizenship in Philadelphia. Local Environment, 15(6), 581-590. doi: 10.1080/13549839.2010.487529

Waisberg, L. G., \& Holzkamm, T. E. (1993). "A tendency to discourage them from cultivating": Ojibwa Agriculture and Indian Affairs Administration in Northwestern Ontario. Ethnohistory, 40(2), 175-211. doi: 10.2307/482201

Wakefield, S., Yeudall, F., Taron, C., Reynolds, J., \& Skinner, A. (2007). Growing urban health: Community gardening in South-East Toronto. Health Promotion International, 22(2), 92101. doi: 10.1093/heapro/dam001

Walsh, C. C. (2011). Gardening Together: Social Capital and the Cultivation of Urban Community. (Doctorate of Philosophy Doctoral Thesis), Case Western Reserve University.

Wang, C.C., \& Burris, M. A. (1997). Photovoice: concept, methodology, and use for participatory needs assessment. Health Education \& Behavior, 24(3), 369-387. doi: $10.1177 / 109019819702400309$

Wang, C. C., \& Redwood-Jones, Y. A. (2001). Photovoice ethics: Perspectives from Flint Photovoice. Health Education \& Behavior, 28(5), 560-572.

Woolcock, M. (2001). The place of social capital in understanding social and economic outcomes. Isuma: Canadian Journal of Policy Research, 2(1), 11-17. 